\title{
Modelling past and future wine production in the Portuguese Douro Valley
}

\author{
C. Gouveia ${ }^{1,2, *}$, M. L. R. Liberato ${ }^{1,3}$, C. C. DaCamara1 ${ }^{1}$ R. M. Trigo ${ }^{1,4}$, A. M. $\operatorname{Ramos}^{1,5}$ \\ ${ }^{1}$ Instituto Dom Luiz, Universidade de Lisboa, 1749-016 Lisboa, Portugal \\ ${ }^{2}$ Escola Superior de Tecnologia, Instituto Politécnico de Setúbal, 2910-761 Setúbal, Portugal \\ ${ }^{3}$ Escola de Ciências e Tecnologia, Universidade de Trás-os-Montes e Alto Douro, 5001-801 Vila Real, Portugal \\ ${ }^{4}$ Departamento de Engenharias, Universidade Lusófona, 1749-024 Lisboa, Portugal \\ ${ }^{5}$ Environmental Physics Laboratory, Universidad de Vigo, 32004 Ourense, Spain
}

\begin{abstract}
Climate is a major factor driving wine productivity in the Douro Valley region of Portugal because vineyards are generally grown under marginal conditions for agricultural production. Using monthly means of climate variables (daily maximum, minimum and mean temperature, diurnal thermal amplitude and daily precipitation) and the normalised difference vegetation index, we analysed the vegetative cycle of vineyards and the vulnerability of Douro wine production to climate variability and change. A good wine production year reflects high photosynthetic activity during spring followed by reduced greenness during summer. Lower precipitation in March has a positive effect during the growing stage, and higher temperatures during late spring are beneficial for production. Two linear regression models were developed with the aim of forecasting Douro wine production at the early (March) and mid-season (July) stages of the vine vegetative cycle. Both models performed well in terms of robustness and reliability. The early season model has the advantage of providing a reliable production scenario immediately after the dormancy stage. All predictors of the mid-season model are meteorological parameters; combined with the very high value $(90 \%)$ of explained variance, this suggests its usefulness to assess the crucial role of climate in wine production. Limitations result from the linear nature of the model, and effects due to the increase in $\mathrm{CO}_{2}$ were disregarded. Nevertheless, our results indicate an increase in production from 1956-1985 to 1986-2006 due to changes in the winter precipitation regime. Moreover, 2071-2100 climate scenarios (A2 and B2) are expected to favour an increase in wine production because of the combined effects of temperature and precipitation in late spring and early summer.
\end{abstract}

KEY WORDS: Normalised difference vegetation index $\cdot$ Portugal $\cdot$ Regional climate model $\cdot$ Vineyard Resale or republication not permitted without written consent of the publisher

\section{INTRODUCTION}

Climate is a major factor driving the spatio-temporal distribution of most agricultural systems, due to their vulnerability to inter-annual climate variability and to climate change. In particular, these systems are very sensitive to changes in traditional patterns of regional climate (e.g. temperature trends or changes in the precipitation regime) but also to extreme events (e.g. heat waves). This is especially true in the case of vineyards in Mediterranean Europe, e.g. in Portugal, as they are generally grown in regions under marginal conditions for agricultural production.
Since vineyards are exposed to a potentially high risk, quality wines are generally associated with optimum climatic conditions (Jones \& Davis 2000). This is the case for the 'Douro wines', which are produced from grapes grown along the Douro Valley, in the old province of Trás-os-Montes e Alto Douro, Portugal (see Fig. 1). Due to the distinctive climatic, topographic and soil characteristics, the Douro region is classified as a denomination of controlled origin (DOC), the highest Portuguese wine classification. In the middle of the 18th century, and with the aim of protecting their interests, Douro farmers asked the administration of the Marquis of Pombal to create the Companhia Geral dos 
Vinhos do Alto Douro. Established by Royal Charter in 1756, the new institution's goal was to ensure the quality of the so-called Port wine and help avoid fraud, balance production and trade, and stabilise prices. Even though the Douro was the third demarcated region after Chianti and Tokay, the 'demarcation of the mountains' established the first wine-producing region in the world, with specific production-based rules. While still primarily associated with Port wine, a fortified wine produced exclusively in the Portuguese section of the Douro Valley, the Douro region produces as much table wine today as it does fortified wine. The present work is focused only on table wines, i.e. those typically referred to as 'Douro wines' and associated with high quality.

Although grapes are an adaptable fruit and are grown around the world, wine quality and production are best in temperate climates. In fact, the role of meteorology and climate parameters in vine growth has long been the subject of research in the fields of biology and phenology, with much of the work examining the influence of air temperature on the composition and quality of grapes (Coombe 1987). For instance, at the global scale, grapevines are traditionally grown in areas with mean temperatures between 12 and $22^{\circ} \mathrm{C}$ during the growing season (Jones 2006), with an optimal vegetative response to daily average values from $20^{\circ} \mathrm{C}$ to $35^{\circ} \mathrm{C}$. Above $35^{\circ} \mathrm{C}$, vegetation activity is impaired, and in some extreme cases, vineyards may suffer serious and permanent damage (Berry \& Björkman 1980, Sepúlveda et al. 1986). Extremes of heat or cold may disrupt the optimum growth cycle or even result in crop losses. During the ripening period, temperature also plays an important role for grape maturation, including the aroma and the colouration (Fregoni \& Pezzutto 2000, Tonietto \& Carbonneau 2004), with a key effect on the final characteristics of the wines (Jackson \& Lombard 1993). Furthermore, vineyards depend on water availability (Carbonneau et al. 1992). Too much precipitation can produce too much vegetation and/or drowned vines, and too much humidity can lead to disease problems, such as downy or powdery mildew. Water availability during critical growth stages also affects grape quality, which in turn impacts wine quality (Conradie et al. 2002).

A number of studies have been conducted from a climatological perspective, with the aim of assessing the effect of climate change on wine quality and yield, at global or regional scales (Jones et al. 2005, Lobell et al. 2006, White et al. 2006). Climatic changes over coastal California (USA), associated with increases in sea surface temperature and water vapour over the Pacific Ocean, may have benefited the premium wine industry, as seen in higher-quality wines and larger grape yields (Nemani et al. 2001). As discussed by Rodó \&
Comím (2000), the inter-annual variability of Iberian wine quality is partially conditioned by large-scale climatic phenomena, such as the North Atlantic Oscillation (NAO) and the El Niño-Southern Oscillation (ENSO). Ramos et al. (2008) showed that changes in temperature are related to wine parameters in northeast Spain, with wine quality being favoured by higher ripening diurnal temperature ranges and reduced production experienced in the warmest vintages. However, despite the detection of such influences, few models are available for grapevine yield and production (Bindi et al. 1996).

A better understanding of the potential impacts of the climate state on natural systems is becoming increasingly important as growing levels of greenhouse gases associated with changes in earth surface features convey temperature and precipitation changes. In the case of Portugal, the observed warming trends are asymmetric with respect to both seasonal and diurnal cycles, with greatest warming occurring with minimum temperatures and during winter and spring (Miranda et al. 2002). Moreover, changes in the regional precipitation regime have been most pronounced in spring with a highly significant decrease of precipitation in March (Trigo \& DaCamara 2000, Gallego et al. 2011) as induced by changes in the predominant location of North Atlantic storm tracks (Paredes et al. 2006, Vicente-Serrano et al. 2011). These studies have also shown that the main driver of precipitation in western Iberia (including the entire Portuguese territory) is the NAO pattern (Hurrell 1995), which steers a large fraction of the transient low pressure systems and consequently modulates most of the precipitation events in the region (Trigo et al. 2004, Trigo 2006). With the aim of evaluating the impact of climate change on wine productivity, Santos et al. (2010) developed a statistical model of grapevine productivity for the Douro region, using climate parameters as predictors. They identified statistically significant correlations between annual yield and monthly mean temperatures and monthly accumulated precipitation during the growth cycle of the vine. However, no parameters associated with grapevine growth (phenology) were used, namely those derived by remote sensing technology that has been developing steadily in the last couple of decades. Agriculture has greatly benefited from remote sensing products, particularly in several applications such as crop identification (Patel et al. 2006), crop growth monitoring and yield prediction (Gouveia \& Trigo 2008) and drought monitoring (Vicente-Serrano et al. 2006, Gouveia et al. 2009). The normalised difference vegetation index (NDVI) is useful for vine growth assessment, and in particular, time series of NDVI imagery efficiently provide a synoptic view of grapevine vegetation dynamics that may be used for vine- 
yard management. Phenological information is essential for decision making during many of the phases of grape growing, namely in labour planning, pest and disease control, canopy management and harvesting (Cunha et al. 2010a). For instance, Cunha et al. (2010a) used 10 d VEGETATION image composites (19992007 ) to examine temporal profiles of NDVI and study their relationship with grapevine phenology. They suggested that NDVI values during the early months of the year are correlated with winegrape production in the Douro region.

Due to the scarce information on external factors influencing Douro wine production and in order to increase our knowledge of this subject, the aim of the present work was to integrate information about phenology, as obtained from remote sensing, with climate conditions in order to develop models for present and future wine production. More specifically, our objectives were as follows:

(1) To analyse the vegetative cycle of vineyards in the Douro region, using the NDVI dataset (at $8 \mathrm{~km}$ resolution) provided by the Global Inventory Monitoring and Modeling System (GIMMS) group.

(2) To assess the impact of temperature and precipitation on the inter-annual variability of vineyard production.

(3) To develop robust multi-linear regression models of wine production, using NDVI and meteorological variables as predictors.

(4) To assess the impact of climate change scenarios on the wine production of the Douro region

\section{Data and pre-processing}

\subsection{Corine Land Cover Map (CLC2000)}

The reference map used here is based on the Corine Land Cover Map (CLC 2000), available on a $250 \times 250 \mathrm{~m}$ grid, which was aggregated from the original vector data at 1:100000. CLC2000 is a key database for integrated environmental assessment and provides a panEuropean inventory of biophysical land cover, using a 44 class nomenclature. This version is available at the site of the European Environmental Agency (www.eea.europa.eu/data-and-maps/ data/corine-land-cover-2000-raster).

Our study area was the Douro region, located in northeastern Portugal (Fig. 1a). The reference map over the selected region was re-projected from the CLC2000 onto geographic coordinates, based on the nearest neighbour scheme (Fig. 1b). Pixels were further geocoded to an $8000 \mathrm{~m}$ grid resolution, based on the mode rule for degradation of thematic maps. This criterion was the most appropriate, since it allows choosing a threshold, thus providing higher confidence in the class label, while maintaining a sufficiently large sample in each class. Accordingly, only 4 pixels were retained with more than $65 \%$ of the area occupied by vineyards (Fig. 1c). Despite the availability of the new CLC2006 version, its usage does not result in choosing different grids for the Douro region.

\subsection{Wine production data}

Annual values of wine production covering the period 1986-2006 were obtained from the Portuguese Statistical Institute (www.ine.pt). Fig. 2 presents the annual averages of whole DOC wine production for the Douro region (excluding Port wine).

\subsection{Vegetation index}

We used the monthly NDVI dataset, at $8 \mathrm{~km}$ resolution, from the advanced very high resolution radiometers (AVHRR) provided by the GIMMS group (http://glcf.umiacs.umd.edu/data/gimms/; Tucker et al. $2004,2005)$. Data for the region cover the area between $10^{\circ} \mathrm{W}$ to $0^{\circ} \mathrm{E}$ and $35^{\circ}$ to $45^{\circ} \mathrm{N}$, and the $26 \mathrm{yr}$ period 1981-2006. Details on the quality of the GIMMS dataset can be found in Kaufmann et al. (2000) and
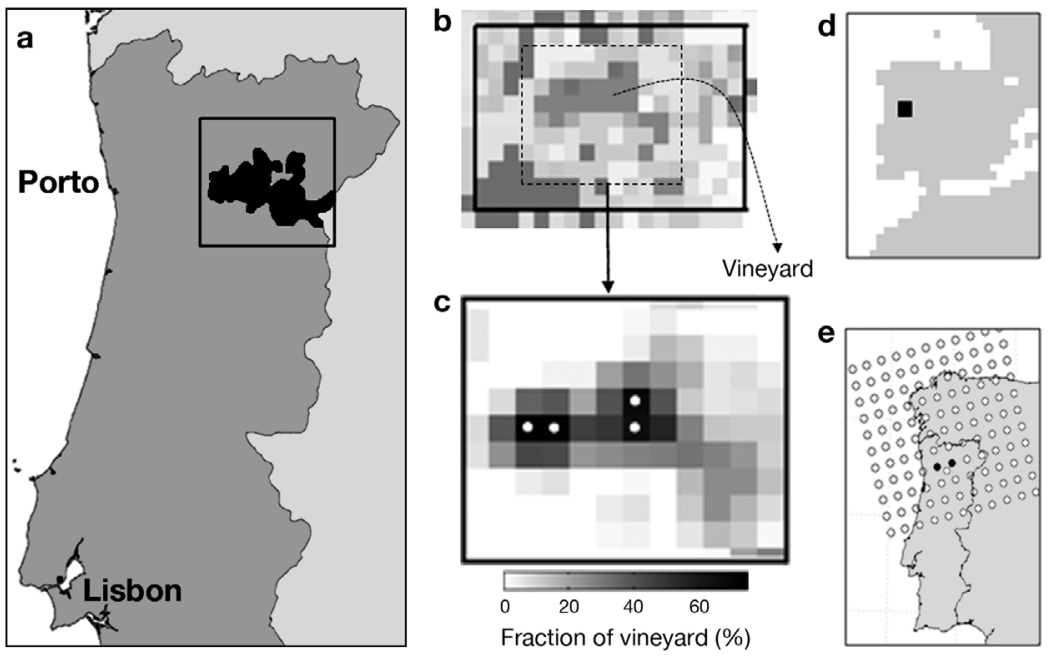

Fig. 1. (a) Douro region (box), (b) pixels coded as vineyards using the Corine Land Cover Map (CLC2000) after the degradation process, (c) identification of the 4 selected pixels (marked by white dots), defined as those with more than $65 \%$ of the area occupied by vineyards, (d) location of the 4 selected pixels from the Climatic Research Unit and (e) location of the 2 grid points from HadRM3 
Zhou et al. (2001). NDVI information was restricted to the $21 \mathrm{yr}$ period that spans 1986-2006, i.e. to the period covered by the wine production dataset, and to the 4 selected pixels where the area is dominated by vineyards. Monthly composites of NDVI and corresponding anomalies for the period considered were then computed for the 4 pixels used.

\subsection{Meteorological parameters}

We relied on fields of monthly averages of maximum, minimum and daily mean temperature (TMAX, TMIN and TAVG) and of precipitation (PREC). The information was extracted from the Climatic Research Unit (CRU TS 3.0) data set (http://badc.nerc.ac.uk/data/cru/), which covers the period 1901-2006 with a spatial resolution of $0.5^{\circ} \times 0.5^{\circ}$. The meteorological data set also was restricted to the study period 1986-2006 and to the 4 closest grid points (Fig. 1d) to the 4 CLC2000 pixels selected. Spatial means were then computed for each month of the time period. In order to assess the impact of climate variability on wine production, we also analysed the inter-annual variability of the selected meteorological parameters during the time period, based on analysis of composite fields.

\subsection{Regional climate model data}

Regional climate models are an important tool to study not only changes in average conditions but also the likelihood of extreme events in certain regions under future scenario projections. In the last decade, the reliability of these projections has been steadily increasing due to advances in modelling and a better understanding of the physical processes of the climate system (Solomon et al. 2007). Among the many climate change projects funded by the EU in the last decade, the PRUDENCE project (http://prudence. $\mathrm{dmi} . \mathrm{dk} /$ ) provided high-resolution meteorological data for Europe (at $50 \mathrm{~km}$ resolution) for both the recent

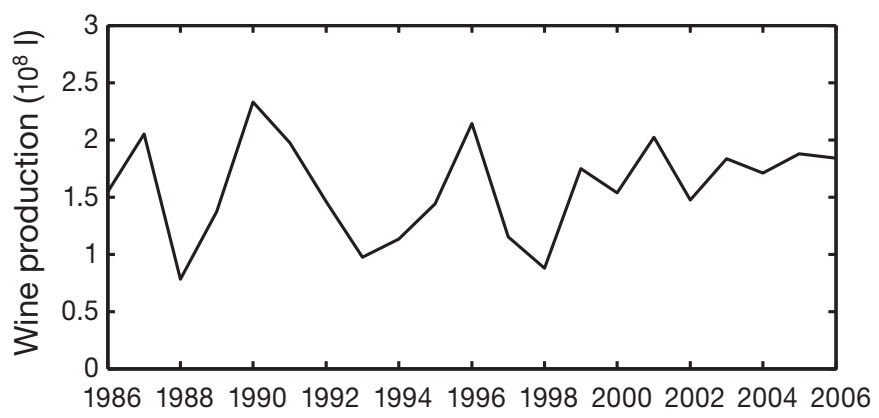

Fig. 2. Time series of wine production in the Douro region for the period 1986-2006 past (control period 1961-1990) and future climates (scenario period 2071-2100). Experiments rely on simulations performed with different regional climate models (Jacob et al. 2007) which are forced by the global atmospheric climate model HadAM3H (Pope et al. 2000, Buonomo et al. 2007). Additional information on the characteristics of the PRUDENCE experiments may be found in Christensen \& Christensen (2007).

Following the approach used in a companion paper (Ramos et al. 2011, this Special), we restricted the analysis to the simulations from the Hadley Centre regional climate model (HadRM3). We used PREC, TMAX and TMIN data from a control period (19611990) and from 2 Intergovernmental Panel on Climate Change (IPCC) emission scenarios: A2 and B2 (20712100). When comparing both scenarios, the A2 scenario considers a higher concentration of $\mathrm{CO}_{2}$, a larger human population, higher energy consumption, scarcer resources and less diverse technology (Nakicenovic et al. 2000). We used monthly averaged values from 2 HadRM3 gridpoints (located closest to the 4 selected vineyard pixels; Fig. 1e), as the seasonal cycles of selected climatic variables for these 2 gridpoints are in good agreement with those of CRU data (data not shown).

Over the Iberian Peninsula, the HadRM3 model presents relatively low precipitation and a positive temperature bias, lower in winter and higher in summer months (Jacob et al. 2007). The bias follows the tendency of the driving global climate model (HadAM3H) used in the PRUDENCE project; this feature of the HadAM3H is discussed in Moberg \& Jones (2004). Despite this weakness, we chose the HadRM3 because previous important climate change studies on Portugal also used the HadRM3 simulations (Santos et al. 2002, Santos \& Miranda 2006, Ramos et al. 2011). A comparison can therefore be made between our results and those from previous studies on Portugal.

\section{COMPOSITE ANALYSIS}

The annual cycle of NDVI monthly mean values is represented in Fig. 3a. Here we adopted the standard hydrological year, spanning from September of year $n-1$ to August of year $n$. In general, January is the month with the highest dispersion of values (indicated by the interquartile range), whereas August and September are the most concentrated. The NDVI cycle of the 4 CLC2000 pixels dominated by vineyards presents a maximum at the end of spring and a minimum during winter, a feature that is related to the typical vegetative cycle of vineyards exposed to an AtlanticMediterranean climate. The harvest period (when the grapes are fully mature) typically occurs in September 
and is followed by dormancy that generally spans October and November. This stage starts with leaf fall and continues over the winter months, leading to budbreak in March (Cunha et al. 2010b). The increment of NDVI between March and June (Fig. 3a) is associated with a period of intensive growth, including budbreak, the production of leaves (Boulton et al. 1996) and flowering, which occurs in May (Cunha et al. 2010b). The flowering date marks the transition from the vegetative to the reproductive physiological process, with the following fruit set period being a crucial stage for grape modelling and vineyard operations (May 2004). Véraison, or the development of the grape and its maturation, usually occurs between July and the first week of August. As shown in Fig. 3a, NDVI values start to decrease in July and continue to decline through the end of the hydrological year, due to the inability of the older leaves to absorb the radiation necessary for photosynthesis (May 2004).
Years associated with high (i.e. above the 75th percentile) and low (i.e. below the 25th percentile) wine production were selected, and a composite of the respective monthly anomalies of NDVI is shown in Fig. 4a. Confidence intervals for anomalies (at the $90 \%$ level) were also computed using a Monte Carlo technique based on the generation of 10000 random samples of 5 yr (i.e. the number of years of high and low production) followed by the estimation of the 10th and 90th percentiles of anomalies. Results indicate that a low wine production year corresponds to lower than normal photosynthetic activity in the previous autumn and the current spring along with higher greenness during the summer.

The annual cycle of monthly means of the meteorological parameters is represented in Fig. 3b-f. Precipitation occurs mainly from September to May, with the highest values observed during autumn and winter months. Precipitation reveals a higher range of inter-
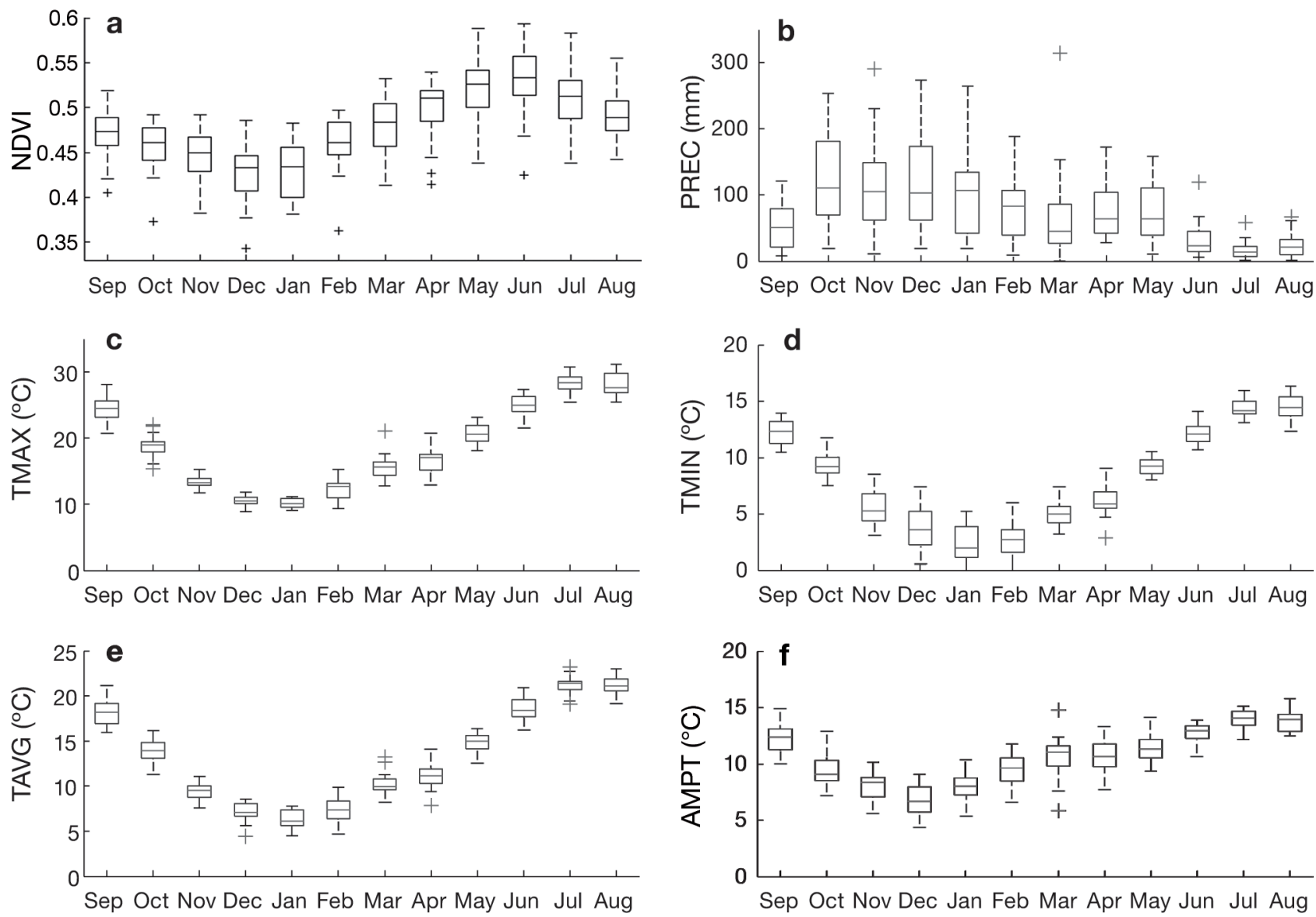

Fig. 3. Annual cycle for the standard hydrological year spanning September of year $n-1$ to August of year $n$ (with $n$ from 1986 to 2006) of (a) monthly normalised difference vegetation index (NDVI) values, (b) monthly values of precipitation (PREC), (c) maximum temperature (TMAX), (d) minimum temperature (TMIN), (e) daily mean temperature (TAVG) and (f) diurnal thermal amplitude (AMPT) for the Climatic Research Unit climate grids representing the Douro Valley region (see Fig. 1d). Boxes delineate median, upper and lower quartiles, with the whiskers representing the lowest and highest observed value still within 1.5 of the interquartile range. +: outliers, i.e. values beyond the ends of the whiskers 

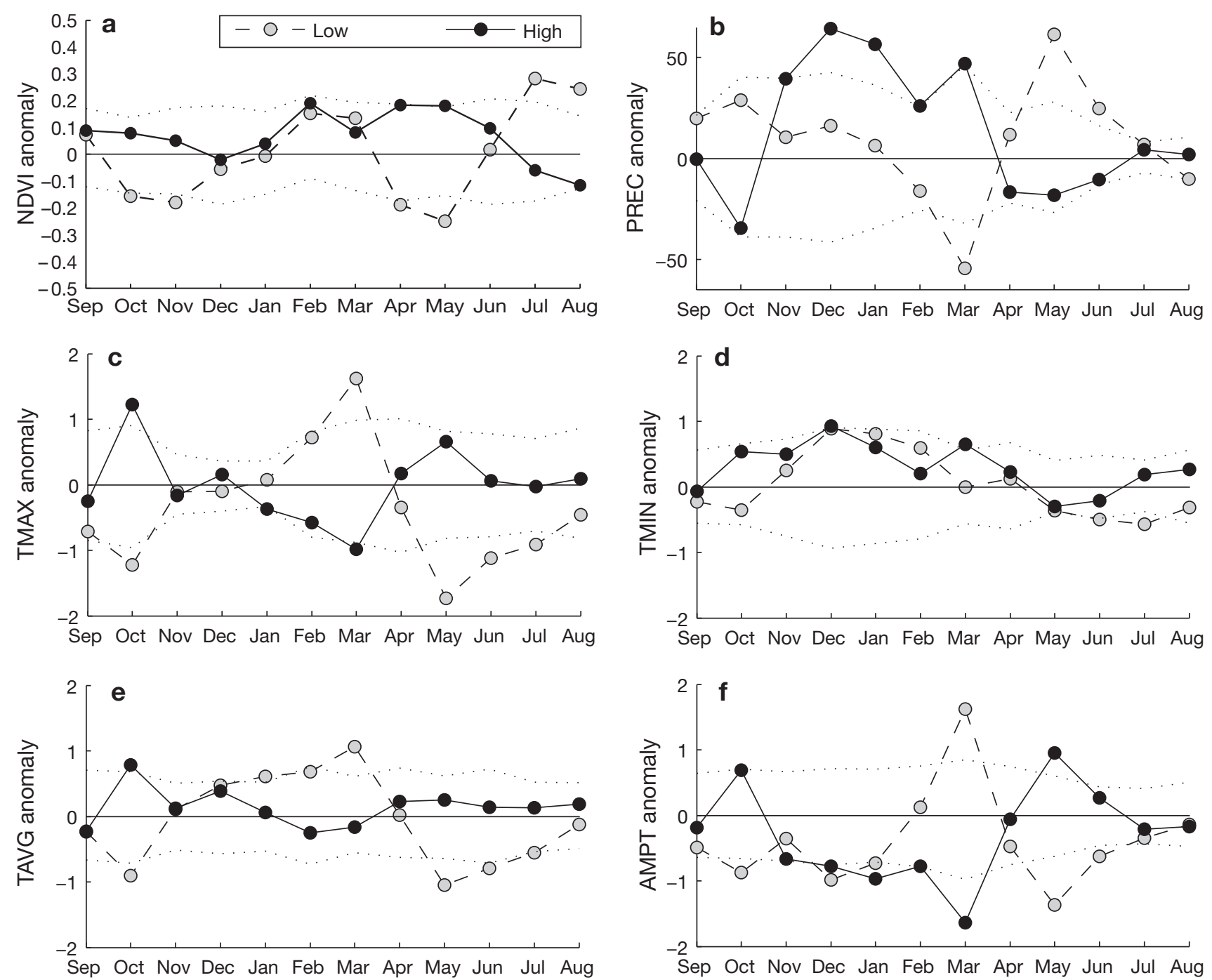

Fig. 4. Annual cycle (as in Fig. 3) of monthly composites of anomalous values of (a) normalised difference vegetation index (NDVI), (b) precipitation (PREC), (c) maximum temperature (TMAX), (d) minimum temperature (TMIN), (e) daily mean temperature (TAVG) and (f) diurnal thermal amplitude (AMPT) with respect to low and high production years for the Climatic Research Unit climate grids representing the Douro Valley region (see Fig. 1d). Dotted lines indicate anomaly intervals at the $10 \%$ and $90 \%$ levels of confidence, as obtained from 10000 random samples of $5 \mathrm{yr}$

annual variability compared to temperature variables. The highest monthly variability in precipitation is observed from October to January, whereas July and August have very low rainfall and low variability. On the other hand, TMAX shows very low variability during the winter months, while TMIN presents the lowest variation in spring and early summer and the highest in winter. As expected, TAVG is lowest in January and highest in August (Fig. 5d). Thermal amplitude (AMPT, calculated as TMAX - TMIN) is high in September, when high diurnal temperatures are good for ripening, flavour and aroma development (Fig. 5e).

Composites for the meteorological variables during years associated with high and low wine production were computed and the corresponding annual cycles of monthly anomalies analysed, since the main differences detected between high and low production years might account for the different development during the stages of growth of the vineyard (Jones 1999). As shown in Fig. 4b-f, the stage of dormancy requires sufficiently cold temperatures to initiate latent bud hardening with limited freeze damage (Nemani et al. 2001). This implies lower than usual diurnal AMPT, i.e. slightly negative anomalies of the quantity 'TMAX TMIN' during winter for years corresponding to higher wine production (Fig. 4f). In fact, winter temperatures are not a problem in Portugal during dormancy, and therefore negative AMPT anomalies from November to March for years corresponding to higher wine production (Fig. 4f) seem to be related to the positive rain- 
fall anomalies in winter from November to March (Fig. 4b), which allow higher soil moisture during spring. This latter feature is associated with higher values of TAVG (Fig. 4e) as well as higher (lower) than usual values of TMIN (TMAX), and therefore higher AMPT particularly in March (Fig. 4c,d). The budbreak stage requires abundant soil moisture and sunshine with temperatures above $10^{\circ} \mathrm{C}$ for sustained vegetative growth. Frost occurrence may reduce bud productivity, leading to poor yields and quality, which is in agreement with the fact that higher than usual values of TMIN during March and April (Fig. 4d) are associated with high production years.

The flowering period requires dry, stable conditions so as not to hinder flower differentiation and berry set. The véraison stage also requires dry conditions (to limit moisture-induced diseases) with moderate temperatures, high levels of insolation and low temperature variability to allow sugars to concentrate leading up to harvest (Nemani et al. 2001). On the other hand, the small or even insignificant differences obtained for July and August are a good indicator that the pre to post bloom is much more important for fruit set and production than the period near véraison. Again, these conditions are in good agreement with the observation that high-production years in the Douro region are associated with negative PREC anomalies during spring (Fig. 4b) as well as a sharp decrease of AMPT after May (Fig. 4f), with positive (but not extreme) anomalies of TAVG (Fig. 4e) and TMAX (Fig. 4c).

In summary, the comparison of NDVI cycles and meteorological parameters for years of low and high wine production revealed significant differences during the following 3 stages:

(1) A first period coinciding with dormancy that starts after harvest. This stage is generally associated with some greenness activity in the vineyard inter-row spaces, which is only possible due to high soil moisture owing to the onset of fall precipitation and/or high temperatures. The high values of precipitation during winter contribute to ensuring high values of soil moisture during the budbreak period, therefore allowing better vineyard growth early in the season. On the other hand, the occurrence of high temperatures during winter may induce drier conditions and early budbreak, which bring greater risk of frost damage.

(2) A second period coinciding with budbreak. During this stage, differences in the NDVI annual curves may be related to the high transparency of the grapevine canopy and to soil cover differences among years (Cunha et al. 2010a). Gouveia et al. (2008) showed that vegetation dynamics during spring and summer in Iberia are mainly driven by winter precipitation with less effect from winter temperatures. However, the effect of the lack of precipitation over a certain period combined with other climatic anomalies, such as high temperatures, high winds and low relative humidities over a given area may result in reduced green vegetation cover (Gouveia et al. 2009). For instance, several authors have provided evidence that budbreak dates occur earlier in the Mediterranean climate due to the higher temperatures during late winter (Boulton et al. 1996, May 2004, Cunha et al. 2010a).

(3) A third period, starting with flowering and continuing during the véraison. After May, the number of days with mean temperature $>10^{\circ} \mathrm{C}$ that are required during the period between flowering and harvest (Boulton et al. 1996, May 2004) is not an issue in the Douro region, but higher production years depend on higher temperature anomalies during this final period.

\section{REGRESSION MODELS FOR WINE PRODUCTION}

Results obtained in Section 3 point out the relationships of the annual cycles of temperature and precipitation with the production of table wine in the Douro region. They further suggest using NDVI together with meteorological variables to develop simple models of wine production based on data covering the period 1986-2006.

A stepwise regression was therefore used to select a set of statistically significant variables (at the $5 \%$ level) to be used as predictors in 2 regression models with the goal of forecasting Douro wine production at early (March) and mid (July) stages of the grapevine vegetative cycle in the region. Problems related to overfitting were mitigated by adopting a leave-one-out scheme for cross-validation (Wilks 1995), i.e. by successively using a single observation from the original sample for validation, and the remaining observations as the training data.

\subsection{Early-season estimates of wine production in the Douro region}

Following the procedure described in the previous paragraph, the stepwise regression was applied to the subset of early-season predictors defined as AMPT, TAVG, PREC and NDVI from September to March. The following multi-linear regression model of earlyseason wine production in the Douro region (ESPD) was obtained:

$$
\begin{aligned}
\mathrm{ESPD}= & 1.02+6.96 \times \mathrm{NDVI}_{\mathrm{Oct}}-0.16 \times \mathrm{AMPT}_{\mathrm{Mar}} \\
& -0.15 \times \mathrm{TAVG}_{\text {Jan }}
\end{aligned}
$$

Results obtained for the period 1986-2006 are presented in Fig. 5, and the observed and modelled time series of wine production show good agreement. As 

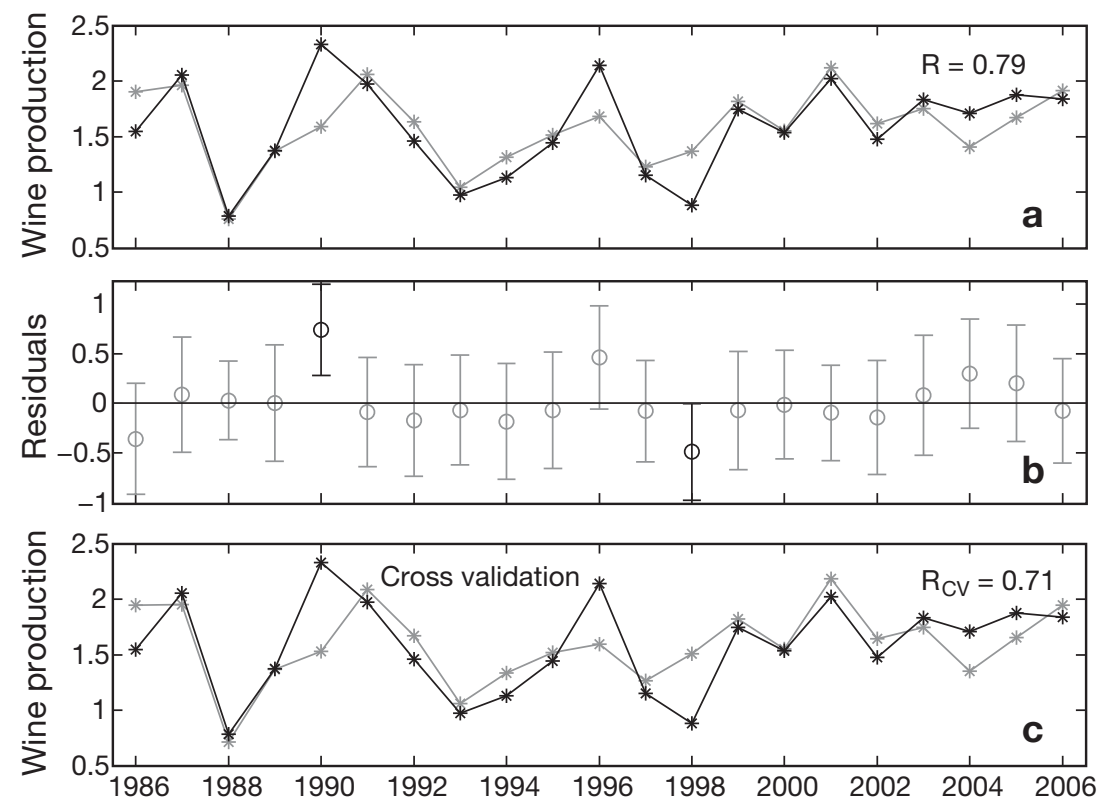

Fig. 5. (a) Observed (light grey curve) wine production in the Douro region and of corresponding modelled values (dark grey curve) when using a linear regression early season model (ESPD) based on the normalised difference vegetation index in October (maximum temperature - minimum temperature in March) and average temperature in January. (b) Residuals and respective 95\% level confidence intervals; 2 outliers (in 1990 and 1998) are highlighted in black. (c) As in (a) except modelled values were obtained from the leave-one-out crossvalidation procedure. All values in $\times 10^{8} 1$

shown in Table 1, the linear model is able to explain $62 \%$ of the total variance of wine production and the adequacy of choosing the model is supported by the small $p$-value $(p=0.0008)$ of the F-test. Results from the leave-one-out cross-validation scheme (Fig. 5) support the robustness of the regression model, given the slight decrease from the value of $\mathrm{R}=0.79$ of the correlation between the observed time series and that fitted by simple regression to the value $R_{C V}=0.71$ (Table 1 ) between the observed time series and the one obtained by cross validation.

The time series of the residuals (observed - modelled) is also shown in Fig. 5, with 1990 appearing as an outlier (at the $95 \%$ confidence level) since the corresponding error bar does not cross the 0 reference line (Chatterjee \& Hadi 1986). The underestimation of the 1990 production by the model may be explained by the low precipitation and the high temperature from January

Table 1. Goodness of fit statistics for early (ESPD) and midseason (MSPD) regression models of wine production in the Douro region. $\mathrm{R}_{\mathrm{CV}}$ : correlation coefficient after cross validation

\begin{tabular}{|lccccc|}
\hline Model & $\mathrm{R}^{2}$ & $F$ & $\mathrm{p}$ & $\mathrm{R}$ & $\mathrm{R}_{\mathrm{CV}}$ \\
\hline ESPD & 0.62 & 9.2 & 0.0008 & 0.79 & 0.71 \\
MSPD & 0.90 & 52.2 & $<0.0001$ & 0.95 & 0.92 \\
\hline
\end{tabular}

to March, which do not favour a good year of wine production (Fig. $4 \mathrm{~b}-\mathrm{f}$ ). However, the impact of such conditions was mitigated by the high values of precipitation in the previous autumn that attenuated the needs of water of the vineyard in the following winter. This feature may be explained by the fact that 1996 is also very close to being an outlier in wine production. However, both years present positive NDVI anomalies in autumn, which may explain how a dry winter (1990) and a wet winter (1996) lead to 2 nearly equal positive outliers.

The overall good performance of the model indicates that the retained predictors contain information about the dormancy period that is relevant for anticipating the stages that follow. In particular, NDVI values in October play an important role and may be regarded as a proxy of the subsequent development of the vineyard, confirming that when grapevines are in their best health conditions as they head into dormancy, this usually leads to more productivity the following year (Cunha et al. 2010a). Furthermore, the low values of AMPT in March, which are related to the positive anomalies of PREC in the previous winter and early spring, are also a good predictor of low vegetative stress conditions. These low values of AMPT in March are associated with higher (lower) than usual TMIN (TMAX).

\subsection{Mid-season estimates of wine production in the Douro region}

The regression model for the mid-season estimates of wine production in the Douro region (MSPD) was obtained by a similar stepwise regression approach, although performed over the set of mid-season variables defined as TMAX, TMIN, TAVG and PREC from September to July. The following model given by:

$$
\begin{aligned}
\text { MSPD }= & -1.10+0.17 \times\left[\mathrm{TMAX}_{\mathrm{Jul}}-\mathrm{TMIN}_{\text {May }}\right] \\
& +0.0051 \times\left[\mathrm{PREC}_{\mathrm{Jan}}-\mathrm{PREC}_{\mathrm{Feb}}\right] \\
& -0.0068 \times\left[\mathrm{PREC}_{\text {May }}+\mathrm{PREC}_{\mathrm{Jun}}\right]
\end{aligned}
$$

was obtained after combining pairs of variables (retained by stepwise regression) in order to diminish the number of predictors (from 6 to 3 ) and hence prevent overfitting problems related to the excessive number of predictors retained (6) for such a relatively short time series (21 yr). 

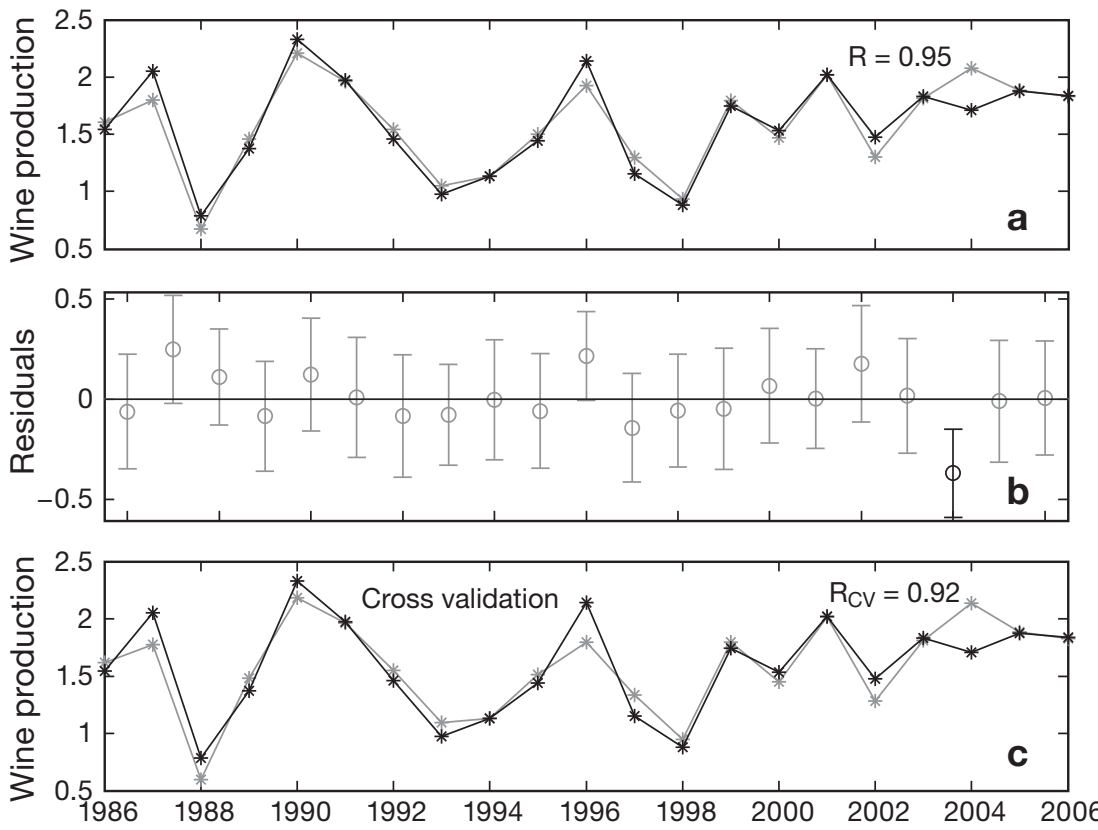

Fig. 6. As in Fig. 5, but using a linear regression mid-season model (MSPD) based on maximum temperature in July, minimum temperature in April and precipitation in January, February, May and June. The single outlier (in 2004) is highlighted in dark grey. All values in $\times 10^{8} 1$

As shown in Table 1 , the very small $\mathrm{p}$-value $(\mathrm{p}<$ 0.0001) of the F-test indicates the strength of the linear model which explains $90 \%$ of the total variance of observed wine production. The good agreement between the observed time series and either the modelled one by simple regression $(\mathrm{R}=0.95)$ and the one obtained by cross-validation regression $\left(R_{C V}=0.92\right)$ is apparent (Fig. 6), and the robustness of the model is supported by the small decrease from $\mathrm{R}$ to $\mathrm{R}_{\mathrm{CV}}$.

The time series of residuals presents a single outlier (at the 95\% confidence level), which corresponds to the year 2004, where the production was overestimated by the model. This may be attributed to the outstanding heat wave that occurred during the 2003 summer (Trigo et al. 2006) and the subsequent negative effect at the beginning of the vineyard vegetative cycle. Again the year 1996 was very close to being an outlier as well, but was underestimated in terms of production when compared with 2004, which was overestimated. The underestimation of 1996 may be attributed to the higher PREC in May, as well as to the lower values of TMAX and TMIN in the same month. This is also consistent with the previous results, which highlight the fact that high AMPT, high TMAX and low PREC during bloom are good for production.

It may be noted that the model uses as predictors the difference between TMAX in July and TMIN in May, the difference between monthly PREC in January and February, and the cumulated PREC in May and June. The positive coefficient affecting the difference between monthly PREC in January and February may be related to the high values of soil moisture required for better growth early in the season followed by lower soil moisture conditions. The subsequent flowering and véraison stages require dry conditions, moderate temperatures in May and a moderately hot early summer, as reflected by the positive coefficients affecting the difference between TMAX in July and TMIN in May and by the negative coefficient affecting cumulated PREC in May and June.

\section{ClimATE CHANGE ASSESSMENT}

As pointed out in Section 1, Portugal has suffered a pronounced decrease in precipitation in the spring, in particular in March, since the early 1950s (Trigo \& DaCamara 2000, Gallego et al. 2011). For temperatures, the observed warming trends have been found to be asymmetric with respect to both seasonal and diurnal cycles. Results reveal a significant increase in extreme heat events for both spring and summer seasons, and a decrease in extreme cold events in winter (Ramos et al. 2011). Observed changes in both temperature and precipitation suggest performing a sensitivity analysis of the effect of such changes on wine production in the Douro region before considering future climate scenarios.

For this purpose we relied on CRU TS 3.0 data for the same 4 grid points chosen to represent the Douro region. Fig. 7 presents thermo-pluviometric anomaly graphics of monthly averages of TMAX and TMIN, as well as of PREC, which were obtained after computing the departures of the period considered in our study (1986-2006) from the previous normal period (19561985). The decrease of PREC in late winter and early spring is worth stressing due to the role of precipitation in the vineyard vegetative cycle, as pointed out in the previous section. The increase in TMAX and TMIN, respectively in late spring and summer, is also worth highlighting given their roles in the MSPD model. Finally, the higher increase in TMAX than TMIN during March is worth noting because of their combined effect on $\mathrm{AMPT}_{\text {Mar }}$ (1 predictand of the ESPD model) as well as the increase in PREC in October because of its links with the increase in $\mathrm{NDVI}_{\text {Oct }}$ (another predictand of the ESPD model).

An assessment of the impact of climate on wine production during the period 1956-1985 may be obtained 

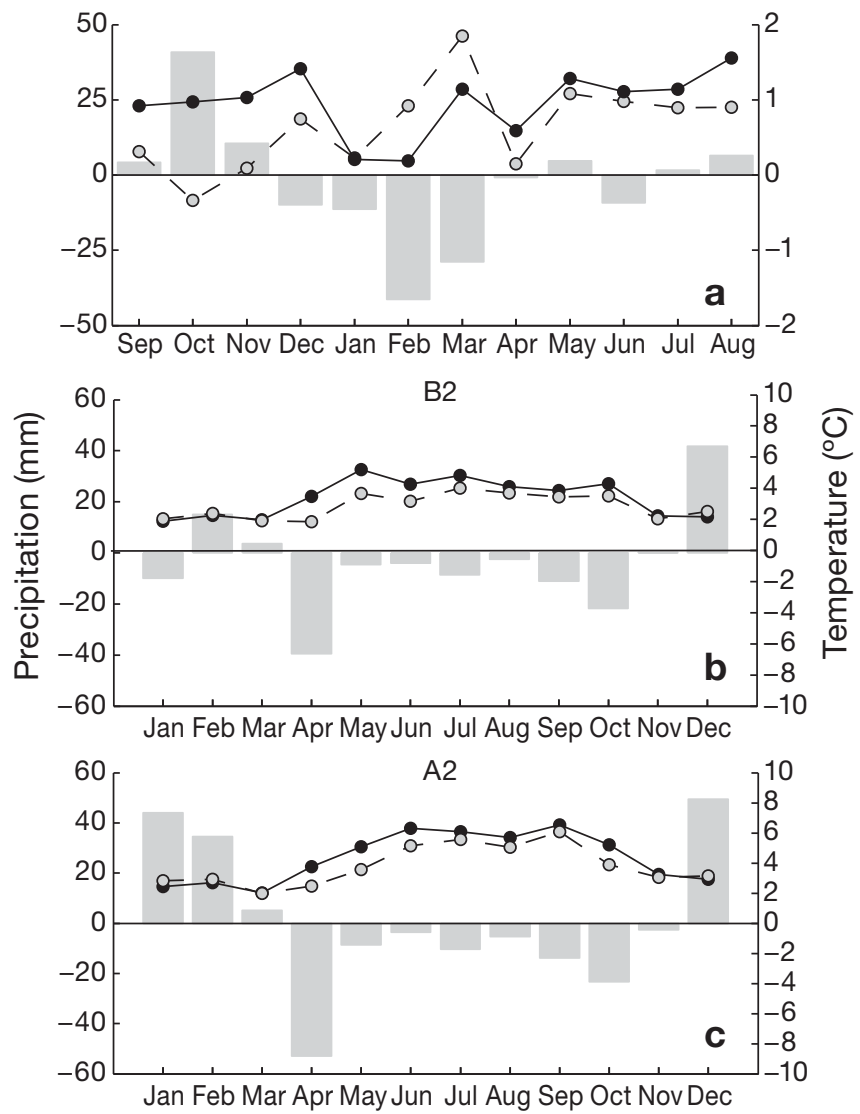

Fig. 7. Monthly thermo-pluviometric graphs of monthly mean anomalies of precipitation (bars), minimum temperature (dashed curve) and maximum temperature (solid curve) for the Climatic Research Unit climate grids representing the Douro Valley region. Anomalies in (a) the study period (1986-2006) relative to the previous normal period (19561985), (b) simulated values for Scenario A2 (2071-2100) relative to those simulated by the control run (1961-1990) and (c) for Scenario B2 values (2071-2100) relative to those of the control run

by feeding the MSPD model with the appropriate observed meteorological variables during that period and by then comparing the obtained statistical distributions of wine production with the observed and modelled ones for the period 1986-2006. The choice of the MSPD over the ESPD model results from the higher value of explained variance obtained with the former.

Obtained values for the mean and SD of MSPD are presented in Table 2. The statistics presented there completely characterise the distributions since the null hypothesis that the 3 considered datasets come from normally distributed populations cannot be rejected at the $5 \%$ level. As expected, the modelled data for the period 1986-2006 have the same mean as the observed production values, and the very small decrease in the $\mathrm{SD}$ reflects the high value of the correlation coefficient $(\mathrm{R}=0.95)$. When the MSPD model is applied to the 1956-1985 period, there is a decrease of $8 \%$ in the
Table 2. Mean and SD of the statistical distributions of wine production $\left(10^{8} 1\right)$ in the Douro region as obtained from observations during the period 1986-2006 and from the mid-season regression model (MSPD) for the periods 1986-2006 and 1965-1985. The percent value in parentheses represents the relative departures of the 1956-1985 mean from the observation period of 1986-2006

\begin{tabular}{|lccc|}
\hline & Obs $_{1986-2006}$ & MSPD $_{1986-2006}$ & MSPD $_{1956-1985}$ \\
\hline Mean & 1.58 & 1.58 & $1.47(-8 \%)$ \\
SD & 0.43 & 0.41 & $0.52(+21 \%)$ \\
\hline
\end{tabular}

mean (lower production) and an increase of $21 \%$ in the variance (higher inter-annual variability) which may be associated with the decrease in the mean of $\left(\mathrm{PREC}_{\mathrm{Jan}}-\mathrm{PREC}_{\mathrm{Feb}}\right)$ from $24.2 \mathrm{~mm}$ in $1986-2006$ to $-5.8 \mathrm{~mm}$ in $1956-1985$, accompanied by an increase in SD from 57.7 to $98.8 \mathrm{~mm}$.

According to Solomon et al. (2007), the annual mean temperatures in Europe are likely to increase more than the global mean during the period 2071-2100, with the warming in northern Europe being largest in winter whilst that observed in the Mediterranean area is largest in summer. The same report also points out that, for the same period, annual precipitation is very likely to increase in most of northern Europe and decrease in most of the Mediterranean area. In addition, a reduced precipitation intensity and earlier onset and longer duration of drought are expected for the southern Iberian peninsula (Beniston et al. 2007).

As shown in an accompanying paper by Ramos et al. (2011), for the 2071-2100 period Portugal is projected to see an average increase in TMAX in summer ranging from $3.2^{\circ} \mathrm{C}$ in the $\mathrm{B} 2$ scenario to $4.7^{\circ} \mathrm{C}$ in the $\mathrm{A} 2$ scenario. An increase of about $3.4^{\circ} \mathrm{C}$ in TMAX in spring is also to be expected in both scenarios. For TMIN, the results are relatively similar, with an increase for summer (spring) ranging from $2.7^{\circ} \mathrm{C}\left(2.5^{\circ} \mathrm{C}\right)$ in the $\mathrm{B} 2$ scenario to $4.1^{\circ} \mathrm{C}\left(2.9^{\circ} \mathrm{C}\right)$ in the $\mathrm{A} 2$ scenario. For Portugal and for the same period, the accumulated PREC on moderately rainy days is expected to decrease, whereas heavier rain tends to be concentrated in the winter season (Santos et al. 2002).

Climate change is expected to have a significant effect on grapevine and wine production (Bisson et al. 2002), that might in turn produce either beneficial or detrimental conditions depending on the region (Jones et al. 2005), a feature that certainly highlights the relevance of regional assessments (Santos et al. 2010). A qualitative assessment of the effect of future climate change on Douro wine production was undertaken here using information from simulations by the HadRM3 as available from the PRUDENCE project. Fig. 10 presents thermo-pluviometric anomaly graphics of monthly averages of TMAX and TMIN as well as 
of PREC with respect to future scenarios A2 and B2, which were obtained after computing the respective departures from the control period.

The decrease in PREC during April-September and the increase during December-March, the latter being especially apparent in the A2 scenario, is worth noting because of its effect on the vineyard vegetative cycle. For temperatures, both TMAX and TMIN increase throughout the year, although TMAX increases more during the spring and growing season than does TMIN. Given the relationships found in the MSPD model, these projected changes are expected to have a further effect on wine production in the Douro.

The effect of climate change on wine production was evaluated by feeding the MSPD model with simulated meteorological variables from 2071-2100 scenarios (A2 and B2) and by then comparing the obtained statistical distributions of wine production with those obtained by the same model when fed with variables from the control run (1961-1990). As shown in Table 3, simulated values of the mean and SD for the control run are considerably larger than those for the observed period 1961-1990. This is attributable to systematic errors of the HadRM3 (as discussed in Section 2.5.), as well as to errors of the MSPD model when applied out of the fitting range of values. Since the normality of the 4 considered datasets cannot be rejected at the $5 \%$ level by Lilliefors' composite goodness-of-fit test, the impact of systematic errors may be mitigated by transforming the $\mathrm{MSPD}_{\text {Control }}$ distribution, $\mathrm{N}(2.54,0.85)$ into a normal distribution similar to the one obtained from MSPD $_{61-90}$, i.e. $\mathrm{N}(1.45,0.52)$ and by then applying the same transformation to the normal distributions $\mathrm{MSPD}_{\mathrm{B} 2}$ and $\mathrm{MSPD}_{\mathrm{A} 2}$. The following transformation

$\operatorname{MSPD}_{X}^{\text {corr }}=$

$\frac{\mathrm{MSPD}_{X}-\left[\operatorname{mean}\left(\mathrm{MSPD}_{X}\right)-\frac{\mathrm{SD}\left(\mathrm{MSPD}_{X}\right)}{\left.\mathrm{SD}_{\left(\mathrm{MSPD}_{61-90}\right)}\right] \times \operatorname{mean}\left(\mathrm{MSPD}_{61-90}\right)}\right.}{\frac{\mathrm{SD}_{\left(\mathrm{MSPD}_{X}\right.}}{\mathrm{SD}\left(\mathrm{MSPD}_{61-90}\right)}}$

(where subscript $X$ stands for Control, A2 or B2 scenarios) was applied accordingly to the corresponding normal distributions. Corrected results are shown in brackets in Table 3 . The obtained increases in the mean of $6 \%$ and $24 \%$, respectively, for the B2 and A2 scenarios, relative to the control run, are worth being emphasised, together with the increase in variability as given by the respective increases of the SD by $4 \%$ and $35 \%$. The estimated increase in wine production that is obtained for both scenarios is attributable to the increase in the mean of $\left(\mathrm{TMAX}_{\mathrm{Jul}}-\mathrm{TMIN}_{\mathrm{May}}\right)$ from $22.4^{\circ} \mathrm{C}$ in the control run to $23.5(24.9)^{\circ} \mathrm{C}$ in B2 (A2) and to the decrease in $\left(\mathrm{PREC}_{\text {May }}+\mathrm{PREC}_{\mathrm{Jun}}\right)$ from $73.0 \mathrm{~mm}$ in the control run to 64.5 (60.7) $\mathrm{mm}$ in $\mathrm{B} 2$ (A2).
Table 3. As in Table 2, but with respect to the distributions obtained from the mid-season regression model (MSPD) when applied to meteorological data for the normal period of 1961-1990, and from simulated data with respect to the control run (1961-1990) and to A2 and B2 scenarios (2071-2100). Values in square brackets are the corrected ones (see Eq. 3) and percent values in parentheses represent relative departures of means and SD from the normal period of 1961-1990

\begin{tabular}{|ccccc|}
\hline & MSPD $_{1961-1990}$ & MSPD $_{\text {Control }}$ & MSPD $_{\mathrm{B} 2}$ & MSPD $_{\mathrm{A} 2}$ \\
\hline Mean & 1.45 & $2.54[1.45]$ & $\begin{array}{c}2.67[1.53] \\
(+6 \%)\end{array}$ & $\begin{array}{c}3.10[1.80] \\
(+24 \%)\end{array}$ \\
SD & 0.52 & $0.85[0.52]$ & $\begin{array}{c}0.89[0.54] \\
(+4 \%)\end{array}$ & $\begin{array}{c}1.15[0.70] \\
(+35 \%)\end{array}$ \\
\hline
\end{tabular}

\section{DISCUSSION AND CONCLUSION}

An analysis was performed on the vegetative cycle of grapevines in the Douro Valley region in Portugal using NDVI together with a set of meteorological variables that included monthly means of TMAX, daily TMIN, daily TAVG, diurnal thermal AMPT and PREC.

We found that the NDVI cycle of the selected vineyard area pixels has a maximum at the end of spring and a minimum during winter. Composites of years of high (low) wine production present positive (negative) NDVI anomalies during the previous autumn and spring, together with negative (positive) anomalies during summer. This feature is an indication that a good year of wine production reflects high photosynthetic activity during the previous autumn and spring followed by reduced greenness and reduced growth during summer. The data set provided by the AVHRR sensor proved to be a valuable tool for vineyard growth monitoring and production modelling, namely for inter-annual comparisons at the regional scale.

The effect of meteorological factors on wine production in the Douro region was also assessed by means of composites of years corresponding to high (low) wine production. We found that high winter rainfall (in March) has a positive impact during the growing stage, whereas higher temperatures during late spring are beneficial for the flowering and véraison stages. The results obtained are in agreement with empirical findings about the roles (and timing) of the different meteorological factors during the stages of the vegetative cycle of grapevines.

Results from the composite analysis suggested developing seasonal statistical forecast models of Douro wine production based on growth (phenology) and meteorological information. Accordingly, 2 linear regression models were developed with the goal of predicting wine production at the early (March) and mid (July) stages of the vegetative cycle of vineyards. 
In the case of the early season model (ESPD) the choice of predictors was restricted until March and those retained were the NDVI in October, TAVG in January and AMPT in March. The model explained $62 \%$ of the total variance in the annual wine production and points to the importance of the dormancy stage of the vineyard, which can condition subsequent growth stages. In turn, the mid-season model (MSPD) was allowed to select predictors until July with the final model improving significantly from ESPD, explaining $90 \%$ of the total variance of wine production. This upgraded model retained as predictors the difference between TMAX in July and TMIN in May, the difference between monthly PREC in January and February, and the cumulated PREC in May and June. Whereas the ESPD model confirms the relevance of a mild, rainy winter and mild March contributing to vine health during the dormancy stage, the MSPD model uncovers the important role of TMIN during May, of PREC at the end of spring (May and June) and of TMAX in July, which is well known to Douro farmers.

From the user's point of view, the ESPD model has the advantage of providing reliable forecasts of production immediately at the end of the dormancy stage, information that would be particularly valuable to farmers, institutions and economists as aid in decision making, in the adoption of technical improvements and even in fraud detection, for instance for insurance companies (Cunha et al. 2010a). On the other hand, the incorporation of NDVI as predictors may be viewed as an indirect support of remote sensing as a valuable assessment tool of the phenological state of the grapevines.

For the MSPD model, the fact that all predictors are meteorological parameters combined with the much higher values of explained variance makes it especially useful to assess the impact of climate variability and change on wine production in the Douro Valley. This quality is especially appealing since a better understanding of the potential effects of climate on natural systems is becoming increasingly important as growing levels of greenhouse gases imply temperature and precipitation changes, which are particularly important in the Mediterranean basin (Solomon et al. 2007, Ramos et al. 2011).

Compared to the production study period of 19862006 , the MSPD model predicted a decrease of $8 \%$ in wine production together with an increase of $21 \%$ in the variance for 1956-1985, which was mainly due to changes in the winter precipitation regime. When the model was applied to the A2 and B2 future climate scenarios, as obtained from the PRUDENCE project, projected values of wine production in the Douro region for 2071-2100 indicated an increase in both the mean and $\mathrm{SD}$, respectively, of $6 \%$ and $4 \%$ for the $\mathrm{B} 2$ scenario, and of $24 \%$ and $35 \%$ for the A2 scenario, relative to the control run (1961-1990). Our results support the fact that future climate change scenarios appear to favour an increase in wine production in the Douro region, in general agreement with the results available from the only other study performed for that wine region (Santos et al. 2010). However, given the spatial differences in climate and production in different regions of the Douro Valley, one would not expect future production to change the same in all areas. For instance, further decreases in rainfall will make it extremely difficult to continue to produce at all in the most eastern area (Douro Superior), while the most western areas (Baixo Corgo and Cima Corgo) might respond more slowly to these changes.

Our results should be analysed with caution due to the limitations imposed by the models (dynamical and statistical) used here and by the simplifications that were made. Concerning the regional modelling, the characteristics of future climate depend highly on the regional model adopted and that the entire northwestern Iberian region is located in the area for which climate change predictions have larger uncertainty, as shown in the latest IPCC report (Fig. 11.5 of Solomon et al. 2007). Furthermore, the HadRM3 model possesses a negative bias in precipitation and a positive bias in temperature (Ramos et al. 2011). Additionally, the statistical forecast models developed also suffer from a few additional issues, in particular the fact that the MSPD model was applied beyond the range of the variable domain where it was fitted. This is a relevant issue taking into account the linear nature of the model used and given the fact that the response of vineyards to climate is nonlinear, like that of most crops. We also did not consider increases in $\mathrm{CO}_{2}$, another important aspect since a higher concentration of $\mathrm{CO}_{2}$ along with interactions with increasing temperatures and decreasing rainfall could have an important impact on the results produced by the model. It is very likely that the response of the grapevine to increased $\mathrm{CO}_{2}$ will be positive, but it may also be affected by lower rainfall and higher temperature. Finally, it is important to bear in mind that factors beyond those related to climatic variability (e.g. technological improvements, environmental issues, soil degradation) were not taken into account, nor were those that might impair vineyard cultivation (e.g. Morecroft \& Keith 2009).

As pointed out by Bisson et al. (2002), climate change is expected to have a significant effect on grape and wine production which might translate into either benefits or disadvantages depending on the region (Jones et al. 2005). According to Duchene \& Schneider (2005), one of the most significant effects of climate change in terms of viticulture in different regions of 
France is that the different phenological stages of grape growth and ripening are being modified, with the period between budburst and harvest becoming both earlier and shorter. The projected changes in ripening have serious consequences if the vineyard enters into the final phase of ripening under increasingly warmer conditions (Deloire et al. 2004), especially if the high temperatures are associated with drought, inhibiting certain physiological processes that are essential for the production of quality grapes. In this context, our results highlight the relevance of regional modelling of past and future wine production and confirm the crucial role played by climate in wine production in the Douro region, providing evidence that climate change scenarios are expected to favour an increase in wine production.

Acknowledgements. This work was partially supported by Project MEDIATIC (PTDC/AAC-CLI/103361/2008) funded by the Portuguese Foundation for Science and Technology (FCT). M.L.R.L. was also supported by a postdoctoral grant from the FCT (SFRH/BPD/45080/2008) and A.M.R. was supported by a doctoral grant from the FCT (SFRH/BD/ 46000/2008). We thank CRU for providing the climate data. The satellite data were provided by GIMMS, and the landcover thematic map was extracted from the CLC2000. Data have also been provided through the PRUDENCE data archive, funded by the EU through contract EVK2-CT 200100132. We are also indebted to 3 anonymous reviewers for their detailed comments and suggestions which helped to improve this paper.

\section{LITERATURE CITED}

Beniston M, Stephenson DB, Christensen OB, Ferro CAT and others (2007) Future extreme events in European climate: an exploration of regional climate model projections. Clim Change 81:71-95

Berry J, Björkman O (1980) Photosynthetic response and adaptation to temperature in higher plants. Annu Rev Plant Physiol 31:491-543

Bindi M, Fibbi L, Gozzini B, Orlandini S, Miglietta F (1996) Modelling the impact of future climate scenarios on yield and yield variability of grapevine. Clim Res 7:213-224

Bisson LF, Waterhouse AL, Ebeler SE, Walker MA, Lapsley JT (2002) The present and future of the international wine industry. Nature 418:696-699

Boulton RB, Singleton VL, Bisson LF, Kunkee RE (1996) Principles and practices of winemaking. Springer, New York, NY

Buonomo E, Jones R, Huntingford IC, Hannaford J (2007) On the robustness of changes in extreme precipitation over Europe from two high resolution climate change simulations. Q J R Meteorol Soc 133:65-81

Carbonneau A, Riou C, Guyon D, Riom J, Schneider C (1992) Agrométéorologie de la vigne en France. Office des Publications Officielles des Communautés Européennes, Luxembourg

> Chatterjee S, Hadi AS (1986) Influential observations, high leverage points, and outliers in linear regression (with discussion). Stat Sci 1:379-416

Christensen JH, Christensen OB (2007) A summary of the
PRUDENCE model projections of changes in European climate during this century. Clim Change 81(Suppl 1): $7-30$

Conradie WJ, Carey VA, Bonnardot V, Saayman D, van Schoor LH (2002) Effect of different environmental factors on the performance of Sauvignon blanc grapevines in the Stellenbosch/Durbanville districts of South Africa. I. Geology, soil, climate, phenology and grape composition. S Afr J Enol Vitic 23:79-91

Coombe BG (1987) Influence of temperature on composition and quality of grapes. Acta Hortic 206:23-35

Cunha M, Marçal RSA, Silva L (2010a) A comparative study of satellite and ground-based vineyard phenology. 29th EARSeL Symp, 15-18 June, Chania, Greece, p 68-77

Cunha M, Marçal ARS, Silva L (2010b) Very early prediction of wine yield based on satellite data from VEGETATION. Int J Remote Sens 31:3125-3142

Deloire A, Carbonneau A, Wang Z, Ojeda H (2004) Vine and water: a review. J Int Sci Vigne Vin 38:1-13

Duchene E, Schneider C (2005) Grapevine and climatic changes: a glance at the situation in Alsace. Agronomie 25:93-99

Fregoni C, Pezzutto S (2000) Principes et premières approches de l'indice bioclimatique de qualité de Fregoni. Prog Agric Vitic 18:390-396

Gallego MC, Trigo RM, Vaquero JM, Brunet M, García JA, Sigró J, Valente MA (2011) Trends in frequency indices of daily precipitation over the Iberian Peninsula during the last century. J Geophys Res 116:D02109 doi:10.1029/ 2010JD014255

Gouveia C, Trigo RM (2008) Influence of climate variability on wheat production in Portugal. In: Soares A, Pereira MJ, Dimitrakopoulos R (eds) Quantitative geology and geostatistics: geoENV VI-geostatistics for environmental applications. Springer, Dordrecht, p 335-347

> Gouveia C, Trigo RM, DaCamara CC, Libonati R, Pereira JMC (2008) The North Atlantic Oscillation and European vegetation dynamics. Int J Climatol 28:1835-1847

> Gouveia C, Trigo RM, DaCamara CC (2009) Drought and vegetation stress monitoring in Portugal using satellite data. Nat Hazards Earth Syst Sci 9:185-195

Hurrell JW (1995) Decadal trends in the north Atlantic oscillation: regional temperatures and precipitation. Science 269:676-679

Jackson DI, Lombard PB (1993) Environmental and management practices affecting grape composition and wine quality: a review. Am J Enol Vitic 4:409-430

Jacob D, Bärring L, Christensen ØB, Christensen JH and others (2007) An inter-comparison of regional climate models for Europe: model performance in present-day climate. Clim Change 81(Suppl 1):31-52

Jones GV (1999) Relationships between grapevine phenology, composition, and quality for Bordeaux, France. Arbor Phaenol 42:3-7

Jones GV (2006) Climate and terroir: impacts of climate variability and change on wine. In: Macqueen RW, Meinert LD (eds) Fine wine and terroir-the geoscience perspective. Geoscience Canada Reprint Series Number 9. Geological Association of Canada, St. John's

Jones GV, Davis RE (2000) Climate influences on grapevine phenology, grape composition, and wine production and quality for Bordeaux, France. Am J Enol Vitic 51:249-261

> Jones GV, White MA, Cooper OR, Storchmann K (2005) Climate change and global wine quality. Clim Change 73: 319-343

Kaufmann RK, Zhou L, Knyazikhin Y, Shabanov N, Myneni RB, Tucker CJ (2000) Effect of orbital drift and sensor 
changes on the time series of AVHRR vegetation index data. IEEE Trans Geosci Rem Sens 38:2584-2597

Lobell DB, Field CB, Cahill KN, Bonfils C (2006) Impacts of future climate change on California perennial crop yields: model projections with climate and crop uncertainties. Agric For Meteorol 141:208-218

May P (2004) Flowering and fruitset in grapevines. Lythrum Press, Adelaide

Miranda PMA, Coelho F, Tomé AR, Valente MA and others (2002) 20th century Portuguese climate and climate scenarios. In: Santos FD, Forbes K, Moita R (eds) Climate change in Portugal: scenarios, impacts and adaptation measures. Gradiva, Lisbon, p 27-83

Moberg A, Jones P (2004) Regional climate model simulations of daily maximum and minimum near surface temperatures across Europe compared with observed station data 1961-1990. Clim Dyn 23:695-715

Morecroft MD, Keith SA (2009) Plant ecology as an indicator of climate and global change. In: Letcher $\mathrm{T}$ (ed) Climate and global change: observed impacts on planet Earth. Elsevier, Amsterdam, p 297-30

Nakicenovic N, Alcamo J, Davis G, de Vries B and others (2000) Special report on emissions scenarios: a special report of Working Group III of the Intergovernmental Panel on Climate Change. Cambridge University Press, Cambridge

Nemani RR, White MA, Cayan DR, Jones GV, Running SW, Coughlan JC, Peterson DL (2001) Asymmetric warming over coastal California and its impact on the premium wine industry. Clim Res 19:25-34

Paredes D, Trigo RM, Garcia-Herrera R, Trigo IF (2006) Understanding precipitation changes in Iberia in early spring: weather typing and storm-tracking approaches. J Hydrometeorol 7:101-113

Patel NR, Bhattacharjee B, Mohammed AJ, Tanupriya B, Saha SK (2006) Remote sensing of regional yield assessment of wheat in Haryana, India. Int J Remote Sens 27:4071-4090

Pope VD, Gallani M, Rowntree PR, Stratton RA (2000) The impact of new physical parameterizations in the Hadley Centre climate model—HadAM3. Clim Dyn 16:123-146

Ramos MC, Jones GV, Martínez-Casasnovas JA (2008) Structure and trends in climate parameters affecting winegrape production in northeast Spain. Clim Res 38:1-15

Rodó X, Comím FA (2000) Links between large-scale anomalies, rainfall and wine quality in the Iberian Peninsula during the last three decades. Glob Change Biol 6: 267-273

Santos FD, Miranda P (eds) (2006) Alterações climáticas em Portugal: cenários, impactos e medidas de adaptação. Gradiva, Lisboa

Santos FD, Forbes K, Moita R (eds) (2002) Climate change in Portugal: scenarios, impacts and adaptation measures. Gradiva, Lisboa

Santos JA, Malheiro AC, Karremann MK, Pinto JG (2010) Statistical modelling of grapevine yield in the Port wine region under present and future climate conditions. Int $\mathrm{J}$
Biometeorol 55:119-131

Sepúlveda G, Kliewer WM, Ryugo K (1986) Effect of high temperature on grapevines (Vitis vinifera L.). I. Translocation of 14590 C-photosynthates. Am J Enol Vitic 37:13-19

Solomon S, Qin D, Manning M, Chen Z and others (eds) (2007) Climate change 2007: the physical science basis. Contribution of Working Group I to the Fourth Assessment Report of the Intergovernmental Panel on Climate Change. Cambridge University Press, Cambridge

Tonietto J, Carbonneau A (2004) A multicriteria climatic classification system for grape-growing regions worldwide. Agric For Meteorol 124:81-97

> Trigo IF (2006) Climatology and interannual variability of storm-tracks in the Euro-Atlantic sector: a comparison between ERA-40 and NCEP/NCAR reanalyses. Clim Dyn 26:127-143

Trigo RM, DaCamara CC (2000) Circulation weather types and their impact on the precipitation regime in Portugal. Int J Climatol 20:1559-1581

Trigo RM, Pozo-Vazquez D, Osborn TJ, Castro-Diez Y, Gámis-Fortis S, Esteban-Parra MJ (2004) North Atlantic Oscillation influence on precipitation, river flow and water resources in the Iberian Peninsula. Int $\mathrm{J}$ Climatol 24: 925-944

Trigo RM, Pereira JMC, Pereira MG, Mota B, Calado MT, DaCamara CC, Santo FE (2006) Atmospheric conditions associated with the exceptional fire season of 2003 in Portugal. Int J Climatol 26:1741-1757

Tucker CJ, Pinzon JE, Brown ME (2004) Global inventory modeling and mapping studies, NA94apr15b.n11-VIg, 2.0. Global Land Cover Facility, University of Maryland, College Park, MD

Tucker CJ, Pinzon JE, Brown ME, Slayback D and others (2005) An extended AVHRR 8-km NDVI data set compatible with MODIS and SPOT vegetation NDVI data. Int J Remote Sens 26:4485-4498

Vicente-Serrano SM, Cuadrat-Prats JM, Romo A (2006) Early prediction of crop production using drought indices at different time-scales and remote sensing data: application in the Ebro valley (North-East Spain). Int J Remote Sens 27: $511-518$

Vicente-Serrano SM, Trigo RM, López-Moreno JI, Liberato MLR and others (2011) The 2010 extreme winter north hemisphere atmospheric variability in Iberian precipitation: anomalies, driving mechanisms and future projections. Clim Res 46:51-65

White MA, Diffenbaugh NS, Jones GV, Pal JS, Giorgi F (2006) Extreme heat reduces and shifts United States premium wine production in the 21st century. Proc Natl Acad Sci USA 103:11217-11222

Wilks DS (1995) Statistical methods in atmospheric sciences. Academic Press, San Diego

Zhou L, Tucker CJ, Kaufmann RK, Slayback D, Shabanov NV, Myneni RB (2001) Variations in northern vegetation activity inferred from satellite data of vegetation index during 1981 to 1999 . J Geol Res 106:20069-20083 